Table 1. RF diagnostic performance in rheumatic diseases

\begin{tabular}{|c|c|c|c|c|c|c|c|c|c|c|}
\hline \multirow[t]{2}{*}{ Group } & \multicolumn{10}{|l|}{$\mathrm{n}$} \\
\hline & & Isotype ${ }^{\star *}$ & $\begin{array}{l}\text { Cut-off } \\
\text { UR/ml }\end{array}$ & Significance & AUC $(95 \% \mathrm{Cl})$ & Sensitivity \% & Specificity \% & Youden Index & $\begin{array}{c}\text { Sensitivity \% } \\
\text { Manufacturer } \\
\text { cut-off + }\end{array}$ & $\begin{array}{c}\text { Specificity \% } \\
\text { Manufacturer } \\
\text { cut-off + }\end{array}$ \\
\hline RA & 22 & $\lg M$ & 135.3 & 0.06 & $0.722(0.604$ to 0.839$)$ & $60 \%$ & 85.2 & 0.45 & 68.2 & 55.5 \\
\hline Psa & 44 & $\lg A$ & 47.2 & 0.074 & $0.698(0.553$ to 0.842$)$ & 54.5 & 81.8 & 0.35 & 54.5 & 77.3 \\
\hline ASP & 44 & $\operatorname{Ig} A$ & 39.5 & 0.080 & $0.668(0.511$ to 0.826$)$ & 54.5 & 88.6 & 0.43 & 54.9 & 79.5 \\
\hline SS & 44 & $\lg M$ & 180.6 & 0.088 & $0.535(0.088$ to 0.708$)$ & 54.5 & 74.4 & 0.28 & 68.2 & 9.3 \\
\hline Healthy & 44 & $\lg M$ & 16.3 & 0.046 & $0.896(0.806$ to 0.986$)$ & 77.3 & 88.9 & 0.66 & 68.2 & 97.8 \\
\hline SLE & 41 & $\lg A$ & 42.6 & 0.073 & $0.701(0.557$ to 0.845$)$ & 54.5 & 85.3 & 0.39 & 54.5 & 73.5 \\
\hline FBM & 35 & $\lg M$ & 68.6 & 0.071 & $0.752(0.612$ to 0.892$)$ & 63.6 & 82.8 & 0.46 & 68.2 & 51.7 \\
\hline $\mathrm{OA}$ & 38 & $\lg M$ & 48.0 & 0.053 & $0.873(0.770$ to 0.976$)$ & 63.6 & 96 & 0.59 & 68.2 & 88 \\
\hline$P G$ & 20 & $\lg M$ & 117.0 & 0.076 & $0.758(0.609$ to 0.908$)$ & 59.1 & 89.5 & 0.49 & 68.2 & 63.2 \\
\hline Total & 332 & & & & & & & & & \\
\hline
\end{tabular}

** The isotype with the best AUC for each clinical scenario. + Manufacturer cut-off value: $20 \mathrm{UR} / \mathrm{ml}$

\section{FRI0588 DIAGNOSTIC PERFORMANCE OF THE RHEUMATOID FACTOR ISOTYPES IN RHEUMATIC DISEASES}

R. Pineda-Sic ${ }^{1}$, D. Vega-Morales ${ }^{1}$, L. Santoyo-Fexas ${ }^{1}$, M. M. CastañedaMartínez ${ }^{1}$, I. D. J. Hernandez-Galarza' ${ }^{1}$, M. A. Villarreal-Alarcón ${ }^{1}$, J. C. Riegatorres ${ }^{1}$, L. Pérez Barbosa ${ }^{1}$, D. E. Flores Alvarado' ${ }^{1}$, M. Eguia Bernal'1, G. Serna-Peña', D. Á. Galarza-Delgado'. ' Universidad Autónoma de Nuevo Léon, Monterrey, Mexico

Background: Rheumatoid Factor (RF) is used for the classification of Rheumatoid arthritis (RA) in patients whose main complaint is hand arthritis but is well known that other conditions have positive RF. Differences in analytical performance between assays were found in previous studies, there was a poor numerical agreement, and using the cut-off proposed by the manufacturer, variation in sensitivity and specificity can be seen. ${ }^{2}$

Objectives: To determine the cut-off value for RF with the best diagnostic performance for RA in patients with hand arthritis compared with their main differential diagnoses.

Methods: Descriptive, cross-sectional, diagnostic test study. Sampling size was calculated 2:1, with the area under the ROC curve (AUC): 0.708 , power $80 \%$ and significance 0.05. Patients with RA, Systemic Lupus Erythematosus (SLE), Osteoarthritis (OA), fibromyalgia (FBM), Polyarticular Gout (PG), Psoriatic Arthritis(Psa), Sjögren Syndrome (SS), Arthralgia suspicious for progression to RA (ASP) and healthy subjects, previously classified with the current criteria by certified rheumatologist were included. EUROINMMUN ${ }^{\circledR}$ assays for RF isotypes IgA, IgM, IgG were used. ROC curves and Youden index for determining the cut-off with the best sensitivity and specificity for each RF isotype comparing RA with other diseases were used. Statistical analyses were performed with SPSS V.24.

Results: Three hundred and thirty-two serum samples from patients were included, in the other rheumatic diseases different from RA, we found positive RF IgM in 141 (45.5\%), 82 (26.5\%) IgA and 25 (8.1\%) IgG. For each clinical scenario

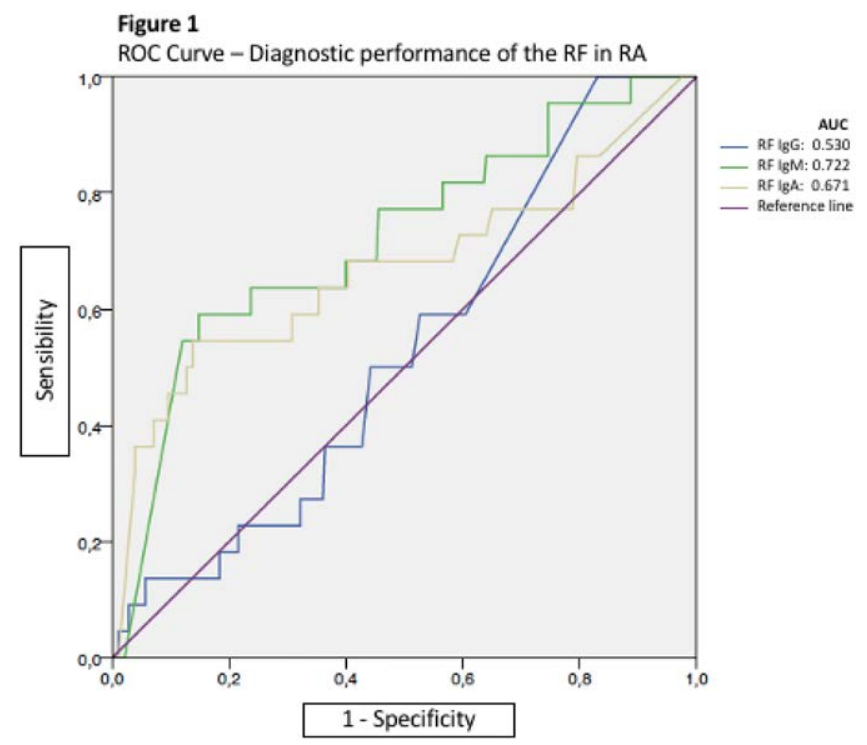

the cut-off with the best sensitivity and specificity was different from the manufacturer proposed, and isotypes with the best diagnostic performance was not the same for each disease, Table 1. We present the ROC curve for RF isotypes in Figure 1.

Conclusion: In order to improve the diagnosis of Rheumatoid Arthritis, different cut-off points of RF and isotypes should be used.

\section{References:}

[1] Van Hoovels L, Jacobs J, Vander Cruyssen B, Van Den Bremt S, Verschueren $P$, Bossuyt X. Performance characteristics of rheumatoid factor and anti-cyclic citrullinated peptide antibody assays may impact ACR/EULAR classification of rheumatoid arthritis. Ann Rheum Dis. 2018;77(5):667-677. doi:10.1136/ annrheumdis-2017-212365

[2] Van Boekel MAM, Vossenaar ER, Van Den Hoogen FHJ, Van Venrooij WJ. Autoantibody systems in rheumatoid arthritis: Specificity, sensitivity and diagnostic value. Arthritis Res. 2002;4(2):87-93. doi:10.1186/ar395.

Disclosure of Interests: None declared

DOI: 10.1136/annrheumdis-2020-eular.4039

\section{FRI0589 CLINICAL ACCURACY OF ANTI- PHOSPHATIDYLSERINE/PROTHROMBIN AND ANTI- BETA2GLYCOPROTEIN I DOMAIN I FOR PREDICTING CLINICAL MANIFESTATIONS OF ANTIPHOSPHOLIPID SYNDROME}

M. Radin ${ }^{* 1}$, I. Cecchi ${ }^{1}$, S. G. Foddai ${ }^{1}$, E. Rubini ${ }^{1}$, A. Barinotti ${ }^{1}$, S. Sciascia ${ }^{1}$, D. Roccatello ${ }^{1}{ }^{1}$ University of Turin, Turin, Italy

Background: Antiphospholipid antibody (aPL) specificities are increasing, however the best accuracy for predicting the clinical manifestations of the diseases is still under debate.

Objectives: To evaluate the clinical accuracy of aPL specificities both individually and/or in combination, to identify a panel of tests that may provide the best accuracy for predicting clinical manifestations of antiphospholipid syndrome (APS).

Methods: We chart-reviewed patients that presented at San Giovanni Bosco Hospital in the last 5 years who tested persistently positive for at least one aPL[1]. Inclusion criteria comprehended: a)Primary APS(PAPS); b) Secondary APS(SAPS), C)aPL positive asymptomatic and d)Patients with clinical manifestations of APS and either inconsistent previous LA positivity and/or low-medium titers aPL(suspect APS).

Results: A total of 122 patients were included in the study 38 PAPS, 31 SAPS, 23 aPL positive asymptomatic and 30 low titers APS patients). Table1 resumes the main clinical and laboratory characteristics of the patients included in the study. All patients were tested for five aPL: criteria aPL, anti-phosphatidylserine/prothrombin(aPS/PT) and anti-Beta2Glycoprotein I Domain I(ß2GPI-D1).

Among the single aPL positivity, $\beta 2 \mathrm{GPI}-\mathrm{D} 1$ showed the best accuracy in predicting the clinical manifestations of APS (AUC 0.639,Cl95\% 0.539-0.74,p=0.011). Similarly, when investigating the possible combinations of aPL panels, the positivity for aPS/PT IgG/IgM and/or $\beta 2$ GPI-D1 showed the best accuracy in predicting the clinical manifestations of APS (AUC 0.698, Cl95\%0.604 -0.793, p<0.001) while triple criteria aPL IgG positivity had the best accuracy for predicting recurrences (AUC 0.720, Cl95\% 0.569-0.871, p=0.012). Results of the ROC curves are illustrated in Figure 1. 